\title{
LETTER
}

\section{The interplay of landscape composition and configuration: new pathways to manage functional biodiversity and agroecosystem services across Europe}

Emily A. Martin, ${ }^{1 *}$ Matteo Dainese, ${ }^{2}$ Yann Clough, ${ }^{3}$ András Báldi, ${ }^{4}$ Riccardo Bommarco, ${ }^{5}$ Vesna Gagic, $^{6}$ Michael P.D. Garratt, ${ }^{7}$ Andrea Holzschuh, ${ }^{1}$ David Kleijn, ${ }^{8}$ Anikó Kovács-Hostyánszki, ${ }^{4}$ Lorenzo Marini, ${ }^{9}$ Simon G. Potts, ${ }^{7}$ Henrik G. Smith, ${ }^{3,35}$ Diab Al Hassan, ${ }^{10}$ Matthias Albrecht, ${ }^{11}$ Georg K.S. Andersson, ${ }^{3}$ Josep D. Asís, ${ }^{12}$ Stéphanie Aviron, ${ }^{13}$ Mario V. Balzan, ${ }^{14,33}$ Laura BañosPicón, ${ }^{12}$ Ignasi Bartomeus, ${ }^{15}$ Péter Batáry, ${ }^{16}$ Francoise Burel, ${ }^{10}$ Berta Caballero-López, ${ }^{17}$ Elena D. Concepción, ${ }^{18}$ Valérie Coudrain, ${ }^{19}$ Juliana Dänhardt, ${ }^{3}$ Mario Diaz, ${ }^{18}$ Tim Diekötter, ${ }^{20}$ Carsten F. Dormann ${ }_{1}^{21}$ Rémi Duflot, ${ }^{22}$ Martin H. Entling, ${ }^{23}$ Nina Farwig, ${ }^{24}$ Christina Fischer, ${ }^{25}$ Thomas Frank, ${ }^{26}$ Lucas A. Garibaldi, ${ }^{27}$ John Hermann, ${ }^{20}$ Felix Herzog, ${ }^{11}$ Diego Inclán, ${ }^{28}$ Katja Jacot, ${ }^{11}$ Frank Jauker, ${ }^{29}$ Philippe Jeanneret, ${ }^{11}$ Marina Kaiser, ${ }^{30}$ Jochen Krauss, ${ }^{1}$ Violette Le Féon, ${ }^{31}$ Jon Marshall, ${ }^{32}$ Anna-Camilla Moonen, ${ }^{33}$ Gerardo Moreno, ${ }^{34}$ Verena Riedinger, ${ }^{1}$ Maj Rundlöf, ${ }^{35}$ Adrien Rusch, ${ }^{36}$ Jeroen Scheper, ${ }^{37}$ Gudrun Schneider, ${ }^{1}$ Christof Schüepp, ${ }^{38}$ Sonja Stutz, ${ }^{39}$ Louis Sutter, ${ }^{11}$ Giovanni Tamburini, ${ }^{5}$ Carsten Thies, ${ }^{40}$ José Tormos, ${ }^{12}$ Teja Tscharntke, ${ }^{41}$ Matthias Tschumi, ${ }^{11}$ Deniz Uzman, ${ }^{42}$ Christian Wagner, ${ }^{43}$ Muhammad Zubair-Anjum ${ }^{44}$ and Ingolf Steffan-Dewenter ${ }^{1}$

\begin{abstract}
Managing agricultural landscapes to support biodiversity and ecosystem services is a key aim of a sustainable agriculture. However, how the spatial arrangement of crop fields and other habitats in landscapes impacts arthropods and their functions is poorly known. Synthesising data from 49 studies (1515 landscapes) across Europe, we examined effects of landscape composition (\% habitats) and configuration (edge density) on arthropods in fields and their margins, pest control, pollination and yields. Configuration effects interacted with the proportions of crop and non-crop habitats, and species' dietary, dispersal and overwintering traits led to contrasting responses to landscape variables. Overall, however, in landscapes with high edge density, $70 \%$ of pollinator and $44 \%$ of natural enemy species reached highest abundances and pollination and pest control improved 1.7- and 1.4-fold respectively. Arable-dominated landscapes with high edge densities achieved high yields. This suggests that enhancing edge density in European agroecosystems can promote functional biodiversity and yield-enhancing ecosystem services.
\end{abstract}

\section{Keywords}

Agroecology, arthropod community, biological control, edge density, pest control, pollination, response trait, semi-natural habitat, trait syndrome, yield.

Ecology Letters (2019)
${ }^{1}$ Department of Animal Ecology and Tropical Biology, Biocenter, University of Würzburg, Am Hubland, 97074 Würzburg, Germany

${ }^{2}$ Institute for Alpine Environment, Eurac Research, Viale Druso 1, 39100

Bozen/Bolzano, Italy

${ }^{3}$ Centre for Environmental and Climate Research, Lund University, 22362 Lund, Sweden

${ }^{4}$ MTA Centre for Ecological Research, Institute for Ecology and Botany, Lendület Ecosystem Services Research Group, Alkotmány u. 2-4, 2163 Vácrátót, Hungary
${ }^{5}$ Department of Ecology, Swedish University of Agricultural Sciences, SE-750 07 Uppsala, Sweden

${ }^{6}$ Commonwealth Scientific and Industrial Research Organisation, Dutton Park, Queensland, Australia

${ }^{7}$ Centre for Agri-Environmental Research, School of Agriculture, Policy and Development, Reading University, RG6 6AR, UK

${ }^{8}$ Plant Ecology and Nature Conservation Group, Wageningen University, Droevendaalsesteeg 3, 6708PB Wageningen, The Netherlands 


\section{INTRODUCTION}

Worldwide, intensive agriculture threatens biodiversity and biodiversity-related ecosystem services (Foley et al. 2005). At a local field scale, monocultures and pesticides restrict many arthropods and plants to non-cropped areas (Geiger et al. 2010). Thus, the majority of organisms that provide key regulating services to agriculture, such as pollination and natural pest control, must colonise fields from non-cropped, semi-natural areas (e.g. road verges, grass margins, hedgerows, fallows), neighbouring fields or in the wider landscape (Blitzer et al. 2012). Semi-natural habitats, however, are often removed to facilitate the use of modern machinery or converted to crops to increase production (Naylor \& Ehrlich 1997), resulting in reduced populations of service-providing organisms (Holland et al. 2016). Consequently, the sustainability of modern food production is increasingly questioned (Garnett et al. 2013).

'Ecological intensification' has the potential to enhance the sustainability of agricultural production by increasing the benefits agriculture derives from ecosystem services (Bommarco et al. 2013). Supporting populations of ecosystem service providers is a key component of ecological intensification (Bommarco et al. 2013). However, we currently lack detailed knowledge on the landscape-scale management choices needed to achieve ecological intensification with a high degree of certainty (Kleijn et al. 2019). For example, semi-natural habitats are prerequisite for many organisms, but effects are often taxon specific. In addition, the presence or abundance of functional groups of organisms in a landscape does not always correlate with the services they provide to crops (Tscharntke et al. 2016; Karp et al. 2018).

The configuration of landscapes (size, shape and spatial arrangement of land-use patches), in addition to their composition (proportion of land-use types), is increasingly suggested as a key factor in determining biodiversity and associated ecosystem services in agricultural landscapes (Fahrig 2013). However, studies have only begun to disentangle the relative roles of the composition vs. the configuration of habitats and
${ }^{9}$ DAFNAE, University of Padova, Viale dell'Università 16, 35020 Legnaro (Padova), Italy

${ }^{10}$ UMR 6553 Ecobio, CNRS, Université de Rennes 1, Campus de Beaulieu, 35042 Rennes Cedex, France

${ }^{11}$ Agroecology and Environment, Agroscope, Reckenholzstrasse 191, 8046 Zurich, Switzerland

${ }^{12}$ Departamento de Biología Animal (Área de Zoología), Facultad de Biología, Universidad de Salamanca, Campus Miguel de Unamuno s/n, 37007 Salamanca, Spain

${ }^{13}$ UMR BAGAP - INRA, Agrocampus Ouest, ESA, 49000 Angers, France

${ }^{14}$ Institute of Applied Sciences, Malta, College of Arts, Science and Technology (MCAST), Paola, Malta

${ }^{15}$ Estación Biológica de Doñana (EBD-CSIC), E-41092, Sevilla, Spain

${ }^{16}$ MTA ÖK Lendület Landscape and Conservation Ecology Research Group, Alkotmány u. 2-4, 2163 Vácrátót, Hungary

${ }^{17}$ Department of Arthropods, Natural Sciences Museum of Barcelona, Castell dels Tres Dragons, Picasso Av, 08003 Barcelona, Spain

${ }^{18}$ Department of Biogeography and Global Change, National Museum of Natural Sciences, Spanish National Research Council (BGC-MNCN-CSIC), CISerrano 115 bis, E-28006 Madrid, Spain

${ }^{19}$ Mediterranean Institute of Marine and Terrestrial Biodiversity and Ecology (IMBE), Aix-Marseille University, CNRS, IRD, Univ. Avignon, 13545 Aix-en-Provence, France

${ }^{20}$ Department of Landscape Ecology, Kiel University, Olshausenstrasse 75, 24118 Kiel, Germany

${ }^{21}$ Biometry\& Environmental System Analysis, University of Freiburg, Freiburg, Germany

${ }^{22}$ Department of Biological and Environmental Sciences, University of Jyväskylä, Jyväskylä, Finland

${ }^{23}$ Institute for Environmental Sciences, University of Koblenz-Landau, Fortstr. 7, 76829 Landau, Germany

${ }^{24}$ Department of Conservation Ecology, Faculty of Biology, Philipps-University Marburg, Karl-von-Frisch Str. 8, 35043 Marburg, Germany

${ }^{25}$ Restoration Ecology, Department of Ecology and Ecosystem Management, Technische Universität München, 85354 Freising, Germany

${ }^{26}$ University of Natural Resources and Life Sciences, Department of Integrative Biology and Biodiversity Research, Institute of Zoology, Gregor Mendel Straße 33, A-1180 Vienna, Austria

\author{
${ }^{27}$ Instituto de Investigaciones en Recursos Naturales, Agroecología y Desar- \\ rollo Rural (IRNAD), Sede Andina, Universidad, Nacional de Río Negro (UNRN) \\ and Consejo Nacional de Investigaciones Científicas y Técnicas (CONICET), \\ Mitre 630, CP 8400, San Carlos de Bariloche, Río Negro, Argentina \\ ${ }^{28}$ Instituto Nacional de Biodiversidad, INABIO - Facultad de Ciencias Agícolas, \\ Universidad Central del Ecuador, Quito 170129, Ecuador \\ ${ }^{29}$ Department of Animal Ecology, Justus Liebig University, Heinrich-Buff-Ring \\ 26-32, D-35392 Giessen, Germany \\ ${ }^{30}$ Faculty of Biology, Institute of Zoology, University of Belgrade, Studentski \\ trg 16, Belgrade 11 000, Serbia \\ ${ }^{31}$ INRA, UR 406 Abeilles et Environnement, Site Agroparc, 84914 Avignon, \\ France \\ ${ }^{32}$ Marshall Agroecology Ltd, Winscombe, UK \\ ${ }^{33}$ Institute of Life Sciences, Scuola Superiore Sant'Anna, Piazza Martiri della \\ Libertà 33, I-56127 Pisa, Italy \\ ${ }^{34}$ INDEHESA, Forestry School, Universidad de Extremadura, Plasencia 10600 \\ Spain \\ ${ }^{35}$ Department of Biology, Lund University, 22362 Lund, Sweden \\ ${ }^{36}$ INRA, UMR 1065 SAVE, ISVV, Université de Bordeaux, Bordeaux Sciences \\ Agro, F-33883 Villenave d'Ornon, France \\ ${ }^{37}$ Animal Ecology Team, Wageningen Environmental Research, Droeven- \\ daalsesteeg 3, 6708 PB Wageningen, The Netherlands \\ ${ }^{38}$ Institute of Ecology and Evolution, University of Bern, CH-3012 Bern, \\ Switzerland \\ ${ }^{39} \mathrm{CABI}$, Rue des Grillons 1, 2800 Delémont, Switzerland \\ ${ }^{40}$ Natural Resources Research Laboratory, Bremer Str. 15, 29308 Winsen, \\ Germany \\ ${ }^{41}$ Agroecology, University of Göttingen, Grisebachstrasse 6, 37077 Göttingen, \\ Germany \\ ${ }^{42}$ Department of Crop Protection, Geisenheim University, Von-Lade-Str. 1, \\ 65366 Geisenheim, Germany \\ ${ }^{43} \mathrm{LfL}$, Bayerische Landesanstalt für Landwirtschaft, Institut für Ökologischen \\ Landbau, Bodenkultur und Ressourcenschutz, Lange Point 12, 85354 Freising, \\ Germany \\ ${ }^{44}$ Department of Zoology \& Biology, Faculty of Sciences, Pir Mehr Ali Shah \\ Arid Agriculture University Rawalpindi, Rawalpindi, Pakistan \\ *Correspondence: E-mail: emily.martin@uni-wuerzburg.de
}


fields within landscapes (Fig. 1; Fahrig 2013; Haddad et al. 2017). Landscape configuration can be measured as the density of edges between crop fields and their surroundings, including neighbouring crops and non-crop areas. Complex landscapes where small and/or irregularly shaped fields and habitat patches prevail have a high density of edges. Due to increased opportunities for exchange, these landscapes are likely to support spillover of dispersal-limited populations between patches (Smith et al. 2014; Fahrig 2017). This may enhance populations' survival in the face of disturbance and their potential to provide services in crops (Boetzl et al. 2019). Furthermore, if landscapes with high edge density are also spatially and temporally diverse in their composition, organisms in these landscapes may benefit from landscape-scale resource complementation and supplementation (Dunning et al. 1992). In this context, areas offering refuges or complementary food resources may encompass uncropped (semi-natural) areas and also neighbouring crops with asynchronous phenology, different host species and/or variable timing and intensity of management interventions (Vasseur et al. 2013; Schellhorn et al. 2015). However, previous studies have found contrasting effects of increasing configurational complexity for different taxa (Concepción et al. 2012; Plećaš et al. 2014; Duflot et al. 2015; Fahrig et al. 2015; Gámez-Virués et al. 2015; Perović et al. 2015; Martin et al. 2016; Bosem Baillod et al. 2017; Hass et al. 2018). Thus, there is currently no consensus on the importance of landscape configuration for arthropods and the services they provide in crops (Seppelt et al. 2016; Perović et al. 2018). Furthermore, interactions between landscape composition and configuration might explain seemingly contradictory results, but have rarely been tested in part due to a lack of independent landscape gradients (but see Coudrain et al. 2014; Bosem Baillod et al. 2017).

Species' responses to environmental filters depend on sets of biological traits ('response traits'), such as diet breadth and dispersal ability, that constrain species' reactions to environmental predictors (Lavorel \& Garnier 2002). The resulting filtering of ecological communities determines the presence or abundance of arthropods able to provide ecosystem services (GámezVirués et al. 2015). Organisms with similar responses to environmental filters may share specific combinations of response traits, known as trait syndromes. Characterising these syndromes and their responses to landscape gradients is critical to predict the consequences of land-use change for biological communities (Mouillot et al. 2013) and the services they provide. However, trait-based responses of arthropods in cropland to landscape gradients have only recently been investigated (Bartomeus et al. 2018; Perović et al. 2018) and cross-taxonomic approaches in agroecosystems are lacking (but see Gámez-Virués et al. 2015). For pollinators, natural enemies and pests in agricultural landscapes, a high diversity of responses due to trait variation within and between groups ('response diversity') is likely to underlie observed abundance patterns. In turn, this may affect our ability to manage landscapes for maximum abundance and/or effectiveness of crop ecosystem service providers and for minimum impacts of pests.

Here, using data from 49 studies covering 1515 European agricultural landscapes and more than 15 crops, we aim to disentangle arthropod responses to landscape gradients and their consequences for agricultural production by performing
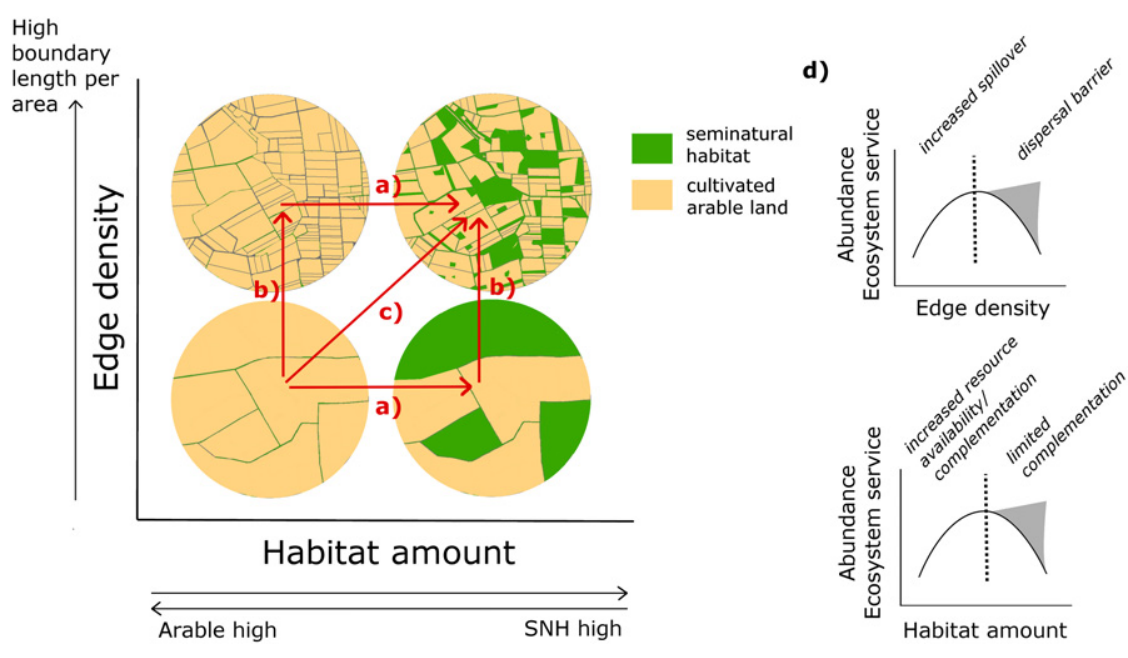

Figure 1 Conceptual representation of the distinction between landscape composition and configuration and their possible effects. Four theoretical farming landscapes are viewed from above (left panel). (a) Landscape composition (increasing habitat amount): an increase in the proportion of semi-natural habitat $(\mathrm{SNH})$ is reflected, in the absence of forest, by a decrease in the proportion of cultivated area as arable land is taken out of production. (b) Landscape configuration (increasing edge density): for the same total amount of crop and non-crop habitat, decreasing patch sizes and complex shapes lead to an increase in the length per area of edges (ecotones) among crop fields and between crop and non-crop habitat. (c) Simultaneous increase vs. interactions: habitat amount and landscape edge density may increase simultaneously, making it difficult to disentangle the contribution of each to biodiversity and ecosystem services. However, these variables are not intrinsically correlated. In addition, interactions may take place that lead to different effects of edge density according to the relative proportion of crop and non-crop habitats in a landscape. (d) Non-linear effects: we hypothesise that effects of landscape composition and configuration on abundance and services are unimodal, with different mechanisms operating at each end of the gradients. For instance, low-resource complementarity due to high amounts of semi-natural habitat, but little cropland may decrease arthropod abundance and/or ecosystem services if organisms benefit from both resource types (e.g. pollinators that benefit from flowering crops or enemies that feed on pest prey, but require resources from semi-natural habitats for reproduction). However, the shape of curve tail ends (grey area) should depend on the state of other variables. For instance, constraints on resource complementation when habitat amount is high should be lifted when edge density increases, facilitating spillover. 
the first empirical quantitative synthesis of the effects of landscape configuration (edge density) and composition (amount of crop and semi-natural habitats) on arthropods and their services in cropland. We include observations of the abundance of pollinators, pests and pests' natural enemies (predators and parasitoids) sampled in fields and their margins and measures of natural pest control, pollination and crop yields. We use landscape predictors calculated similarly for all studies from high resolution maps with standard land use-land cover classification. We test the following predictions:

1 Within functional groups of pollinators, pests and natural enemies, responses to landscape predictors differ among trait syndromes. Thus, considering key trait syndromes of arthropods should increase our ability to predict the effects of landscape variables on functional groups. On one hand, species that use specific crop or non-crop resources should benefit from increased proportions of these resources (habitats) in the landscape (Tscharntke et al. 2012). On the other hand, species with medium to low dispersal ability and diet or habitat needs outside crops should be most abundant in fields and margins of landscapes with high edge density, due to shorter travel distances and/or greater resource complementation between habitats and crops (Smith et al. 2014).

2 Effects of landscape composition and configuration interact. Increasing resources in surrounding arable and semi-natural areas should support arthropods and arthropod-driven services in crops most effectively when travel distances are short (edge density high), promoting spillover between surrounding areas and crops. Furthermore, short travel distances promoting spillover may compensate for scarce arable or semi-natural resources. Consequently, positive effects of edge density on abundance and services in crops may be strongest at low amounts of non-crop habitat (Fig. 1; Holland et al. 2016).

3 Effects of landscape variables on arthropods and services are hump-shaped across Europe (Fig. 1d; Concepción et al. 2012). Indeed, resource complementation may be optimal at intermediate habitat amount, but insufficient at high amounts of crop or non-crop habitat (Tscharntke et al. 2012). Similarly, edges may facilitate spillover at low to medium density, but hinder dispersal at high edge density due to barrier effects (e.g. in the presence of hedges; Wratten et al. 2003) or high spatiotemporal heterogeneity of the agricultural mosaic (Díaz \& Concepción 2016). Due to interactions (prediction 2), decreases in abundance or services at extreme values of habitat amount may be lifted under conditions of high edge density and vice versa (shaded grey areas in Fig. 1d).

To date, interactive and nonlinear effects of landscape variables on arthropods have rarely been explored, and, to our knowledge, never in the context of trait-based responses to landscape gradients. We test these predictions for a broad range of taxa and three production-related ecosystem services. We show that the diversity of responses to landscape variables is high among pollinators, enemies and pests, and effects of landscape composition and configuration depend on each other. But overall, high landscape edge density benefitted a large proportion of service-providing arthropods. It was also positive for service provision and harmful for pests, indicating a landscapescale solution for ecological intensification that does not require setting aside large amounts of arable land and comes with strong benefits for arthropod functional diversity.

\section{MATERIALS AND METHODS}

\section{Data collection and collation}

Data holders were approached through networks of researchers with the aim of collecting raw data from a representative sample of studies performed in European crops. After initial collection, data were screened for missing countries or crops systems, and requests were targeted at researchers having published in these areas. Of 77 proposed studies, 58 provided data with sufficient site replication and high resolution land-use maps (Table S1, Appendices S1, S2 in Supporting Information). Requested data were arthropod abundance per unit area and time (species richness when available) and measures of pollination, pest control and yields, sampled along gradients of landscape composition and configuration in $\geq 8$ sites. Sites included annual and perennial crop fields, managed grasslands, field margins and orchards. Farms were conventional, low-input conventional or organic. Data were collated and standardised as described in Appendix S1. After preliminary analyses, we excluded organic sites because few studies compared conventional and organic farms in similar landscapes. This led to a total of 49 studies and 1,637 site replicates from 1,515 distinct landscapes (circular map sectors; Appendix S1, Fig. S1), some sites having been sampled in multiple studies.

\section{Landscape variables}

We used land-use maps provided by data holders to calculate landscape variables for all studies. First, we standardised map classification to five land-use classes (arable, forest, semi-natural habitat, urban and water). Semi-natural habitat included hedges, grassy margins, unmanaged grasslands, shrubs, fallows (Appendix S1). We then calculated variables in six circular sectors of $0.1-3 \mathrm{~km}$ radius around sites (Appendix S1, Fig. S1). Several indices can be used to describe landscape composition, including $\%$ arable land and \% semi-natural habitat $(\mathrm{SNH})$ (e.g. Chaplin-Kramer et al. 2011). To test the importance of these land-use classes, we selected $\% \mathrm{SNH}$ and $\%$ arable land as measures of landscape composition and used them in parallel sets of models to avoid collinearity (see Statistical analyses).

Similarly, several measures of landscape configuration exist. Among them, the density of edges available for exchange between landscape patches theoretically underpins mechanisms of spillover and resource complementarity for biodiversity and services (see Introduction) and has been frequently used in other studies (e.g. Holzschuh et al. 2010; Concepción et al. 2012). We thus measured landscape configuration as the total length of edges per area of each landscape sector (edge density ED, in $\mathrm{km} / \mathrm{ha}$ ) between crop fields and their surroundings. Hereby, we consider the combined effects of crop/crop (between fields) and crop/non-crop edges (Fig. 1). Both interfaces may enhance arthropod movements in and out of fields (Schellhorn et al. 2015). At radii up to $0.5 \mathrm{~km}$, ED is negatively related to mean field size and positively to the density of edges per area of arable land (Fig. S2). Importantly, ED reflects the grain of whole landscapes including non-crop elements and crops. Thus, landscapes with high ED have comparatively small fields and non-crop patches. A decrease in ED is related to an increase in size of both field and/or non- 
crop patches, and reflects a lower total density of edges available for exchange in the whole landscape.

\section{Functional groups and arthropod traits}

We classified above-ground arthropods into functional groups of pollinators, pests and natural enemies of pests (Appendix S1, Table S2). Organisms that are predators or herbivores as larvae, but pollinators as adults, were classified according to the life stage sampled. Arthropods that could not be classified into these groups (Appendix S1) were included in analyses of total arthropod abundance, as they contribute to overall farmland biodiversity, but not in separate analyses of pollinators, pests and natural enemies (see Statistical analyses).

Six categorical traits associated with dispersal mode, overwintering behaviour and diet were hypothesised to influence the response of arthropods to landscape variables, as they relate to the need and/or ability to move or disperse between habitat types to access food, hosts, nesting or overwintering resources (Table 1). We defined traits for all arthropod species or families according to the availability of information on separate taxa and to data set resolution (Appendix S1, Table S2; 36 of 58 data sets provided species-level identification). We used hierarchical cluster regression to identify parsimonious combinations of shared traits for organisms with shared responses to landscape filters (Appendix S1; Kleyer et al. 2012). These combinations are defined as trait syndromes characterising different responses of species groups to the environment (see Introduction). As trait syndromes may vary according to the functional group (Lavorel \& Garnier 2002), we identified them separately for pollinators, natural enemies and pests (Figs S3, S4). Trait syndromes are defined parsimoniously based on one or a few trait combinations. However, all traits contribute to whole syndrome definition and are described in Figs S3, S4.

\section{Statistical analyses}

We calculated arthropod abundance in each site at three nested levels of community structure (all arthropods; pollinators, enemies and pests; trait syndromes within functional groups;
Appendix S1). Pest control, pollination and yields were available from a subset of studies (Table S3). For this subset, we calculated an ecosystem service index representing the amount of service provided (Appendix S1). We analysed the effects of landscape predictors on arthropod abundance and services using linear mixed effects models in R package lme4 v.1.1-15 (Bates et al. 2015). We focused on abundance because it has been found to drive ecosystem service provision (Winfree et al. 2015). However, abundance and species richness were positively related across groups (estimates of linear mixed models relating richness to abundance using $\ln (\mathrm{x}+1)$-transformed data, with random intercept for study and year: $0.4 \pm 0.01, P<0.001$ for all arthropods, pollinators and enemies). We $\ln (\mathrm{x}+1)$-transformed abundance and services to meet assumptions of normality and homoscedasticity. Predictors were \% SNH and \% arable land as measures of landscape composition and edge density as measure of configuration. We expected changes at low values of predictors to have more impact than at high values; thus, we $\ln (\mathrm{x}+1)$ transformed the predictors. This transformation improved model fits $\left(R^{2}\right.$, see below) and was maintained for all analyses.

To account for collinearity of composition variables (Fig. S2), we performed two sets of models including either \% SNH or $\%$ arable. Correlations between edge density and composition variables were low within and across studies (Fig. S2; mean within-study Spearman rho 0.05, SD 0.2, mean variance inflation factor of models with all arthropods 2.7, SD 1.8), but some studies showed high correlation in specific years and scales (Table S4). We thus ran analyses including and excluding these studies. As no differences were found in overall results, we present analyses including all studies (Appendix S1).

Full models took into account hypotheses of a) interactions between landscape variables and b) nonlinearity by including quadratic model terms (Appendix S1). To reflect the ranges covered by European landscape gradients, we did not standardise landscape predictors within studies. In this way, we were able to capture nonlinear effects across full gradients, that is, that responses to landscape change within studies may differ across full European gradients in landscape composition and configuration (Van de Pol \& Wright 2009). For comparison, we evaluate effects using (1) landscape variables mean-

Table 1 Functional response traits included in cluster analyses. Details on classification of traits for all organisms are provided in Appendix S1, Table S2. The full database of traits for all species is published at https://doi.org/10.5061/dryad.6tj407n

\begin{tabular}{|c|c|c|c|}
\hline Trait name & Trait level & Abbreviation & Description \\
\hline \multirow[t]{2}{*}{ Diet breadth } & Specialist & (specialist) & Diet restricted to no more than two families of host plants or prey* \\
\hline & Generalist & (generalist) & Generalist diet including a broad range of families \\
\hline \multirow[t]{2}{*}{ Agricultural specialism } & Yes & (agsp) & Diet specialists for which hosts or prey are agricultural (crops or pests) \\
\hline & No & (non agsp) & Diet generalists or diet specialists for which hosts or prey are not agricultural \\
\hline \multirow[t]{2}{*}{ Diet life history } & Same diet & (same diet) & Organisms have a similar diet across their life cycle \\
\hline & Different diet & (diff. diet) & Organisms switch diets between life stages (e.g. carnivore larva to nectarivore adult) \\
\hline \multirow[t]{2}{*}{ Overwintering habitat } & Crop & (crop) & Organisms may overwinter in or outside crops \\
\hline & Non crop & (non crop) & Organisms overwinter mainly outside crops \\
\hline \multirow{4}{*}{ Dispersal } & Ground & (gd) & Dispersal by moving on the ground (wingless or undeveloped wings) \\
\hline & Flight & (flight) & Dispersal by active flight (organisms with developed wings) \\
\hline & Flight/wind & (fl/wind) & Active flyers known to disperse on wind currents \\
\hline & Wind & (wind) & Dispersal by wind or electrostatic currents (ballooning spiders) \\
\hline \multirow{2}{*}{ Stratum } & Ground/vegetation & (ground/veg) & Forages by walking or building webs on the ground or in vegetation \\
\hline & Aerial & (aerial) & Forages by flying between target hosts \\
\hline
\end{tabular}

*Diet restricted to one larval 'microhabitat' for hoverflies; see Appendix S1. 
centred within studies and (2) standardised response variables in Appendix S3.

We accounted for the data's hierarchical structure by including random effects for study and year, sampling method and block (Appendix S1) and scaled predictors across studies by mean-centring and dividing them by two standard deviations (R package arm v.1.9-3, Gelman \& Su 2016). We ran separate models at successive scales of $0.1,0.25,0.5,1,2$ and $3 \mathrm{~km}$ radius around fields. Results at all scales (estimates and boot-strapped $95 \%$ confidence intervals $[\mathrm{CI}]$ of full models) are presented Figs S5-7. Figures 2-4 illustrate results at $1 \mathrm{~km}$ radius. We calculated $\mathrm{R}^{2}$ of the models as the variance explained by fixed (marginal $R^{2}, R^{2} \mathrm{~m}$ ) and by fixed and random terms (conditional $R^{2}, R^{2} \mathrm{c}$ ) respectively (Nakagawa \& Schielzeth 2013). Successive spatial scales are inherently correlated, and results at one scale are likely to be reflected at other scales (Martin et al. 2016). In results, we focus interpretation on effects that were significant (CI do not overlap zero) at more than one scale, as these indicate robustness across scales and have the broadest implications for landscape management (Pascual-Hortal \& Saura 2007).

Few studies sampled all taxa and services in the same sites. To avoid lack of common support for contrasts (e.g. a functional group sampled only in a portion of the overall gradient; Hainmueller et al. 2018), we performed separate models for each functional group and service. Replicate numbers for all responses and sites are provided in Tables S5, S6. Residual normality and homoscedasticity were validated graphically. We verified the absence of residual spatial autocorrelation using spline correlograms across studies (Zuur et al. 2009). Statistical analyses were performed in R Statistical Software v. 3.4.1 (R Core Team 2017).

\section{RESULTS}

\section{Abundance of arthropods and functional groups}

We synthesised the effects of landscape predictors on the abundance of 132 arthropod families, encompassing over 494120 individuals and 1,711 identified species or morphospecies. Of these individuals, 50, 10 and $37 \%$ were classified as natural enemies, pollinators and pests respectively $(44,33$ and $1 \%$ of species; Table S2). Effects of \% SNH on arthropod abundance were convex at high edge density (Fig. 2, Fig. S5). Effects of edge density depended on \% SNH and led to a twofold increase at high $(>20 \%)$ and 1.6-fold increase at low $(<2 \%) \mathrm{SNH}$. However, in landscapes with low edge density, increasing \% SNH had no effect on arthropod abundance.

Pollinators, natural enemies and pests showed distinct patterns when considered separately (Fig. 2). Pollinators showed a similar convex effect of $\% \mathrm{SNH}$ and a negative effect of $\%$ arable land (Fig. S5), but effects were scarce on all natural enemies or all pests. The conditional $\mathrm{R}^{2}$ of these models was high (mean maximal $R^{2}$ c across scales 0.80 , SD 0.06), but the variance explained by landscape predictors was low (mean maximal $R^{2} \mathrm{~m}$ across scales 0.04 , SD 0.03 ). However, breaking up these groups into trait syndromes led to further differentiation and a clearer picture.
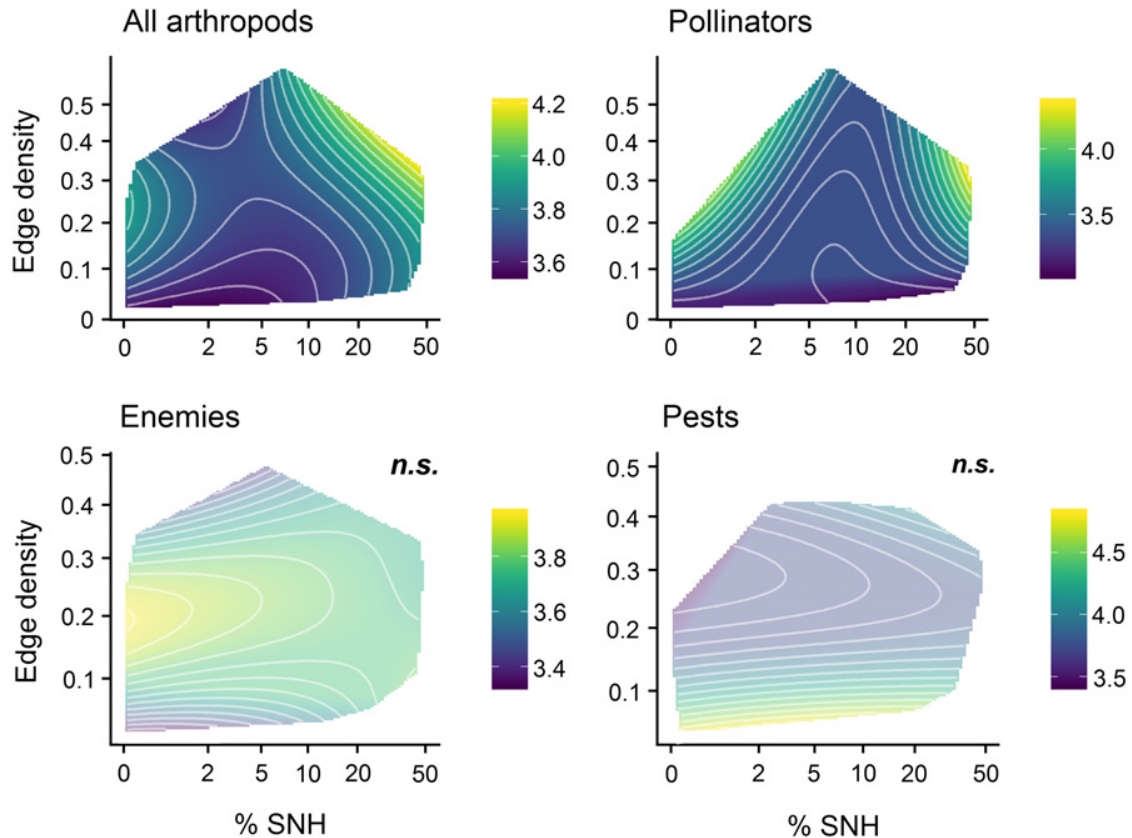

Figure 2 Heatmaps of the effects of semi-natural habitat amount (SNH; composition variable) and landscape edge density (ED in km/ha; configuration variable) on the abundance of arthropods (top left) and on functional groups of pollinators, natural enemies and pests. The heatmaps can be read like a topographic map, with yellow peaks and blue valleys, and steeper slopes where line density is high. Yellow indicates areas of highest abundance; blue indicates areas of lowest abundance (see $\ln (\mathrm{x}+1)$-transformed abundance scale at the right of each panel). Estimates and $95 \%$ confidence intervals $(\mathrm{CI})$ of effects are shown for all radii in Fig. S4. Results at $1 \mathrm{~km}$ radius are shown here. Results are not interpreted (marked 'n.s.' and faded) if significant effects were obtained at less than two of six tested radii. Only the area covering the range of both variables for each response is plotted. Note a log-scale of predictor variables. 


\section{(a) Natural enemies}

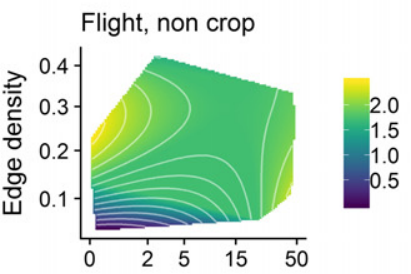

Flight/wind, non crop

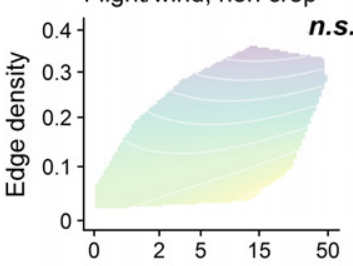

Gd, non crop

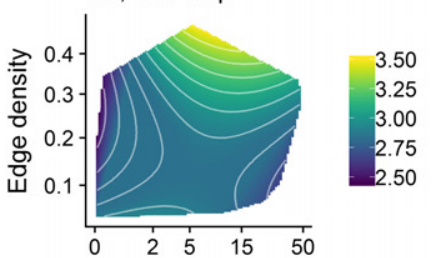

Wind, non crop

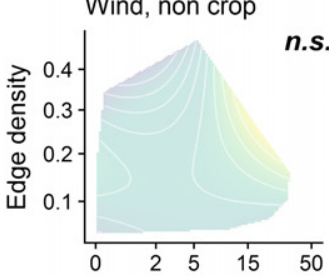

Flight, crop

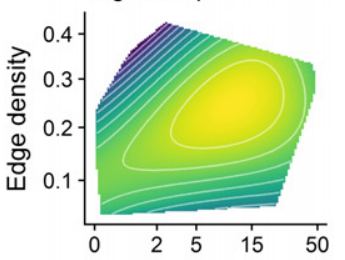

Gd, crop

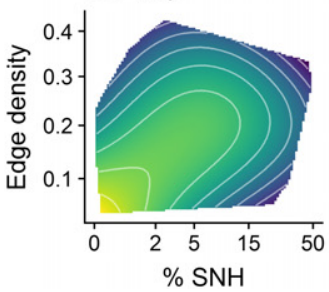

n.s.
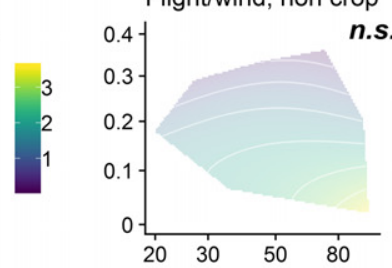

Gd, non crop

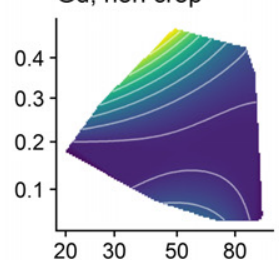

Wind, non crop

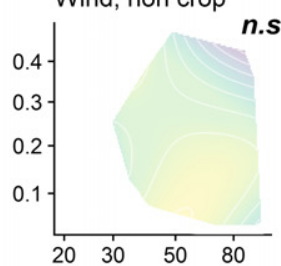

n.s.
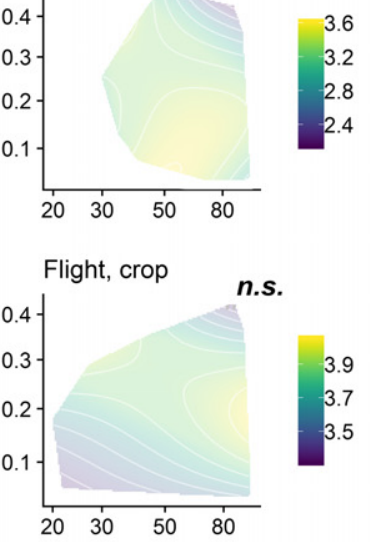

Gd, crop
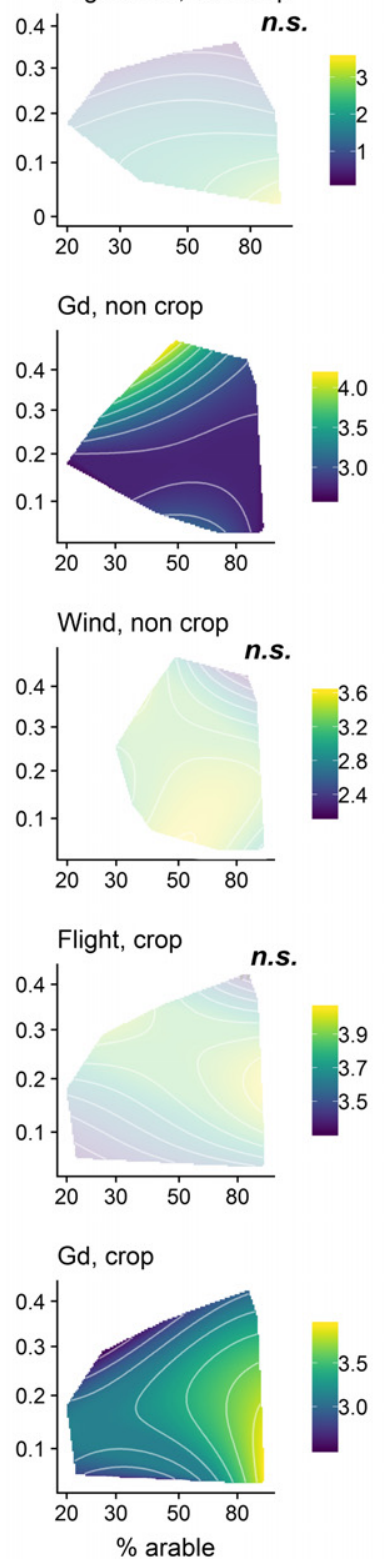

(b)
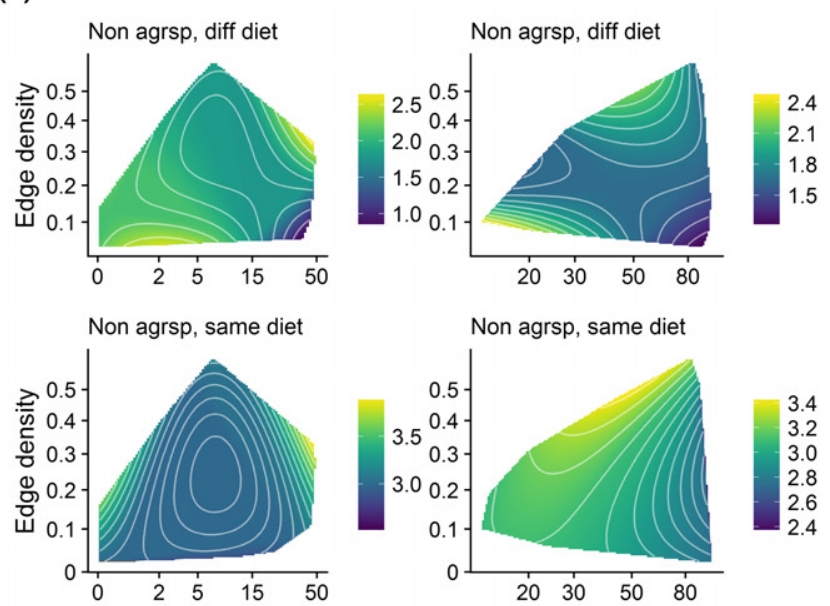

Non agrsp, same diet
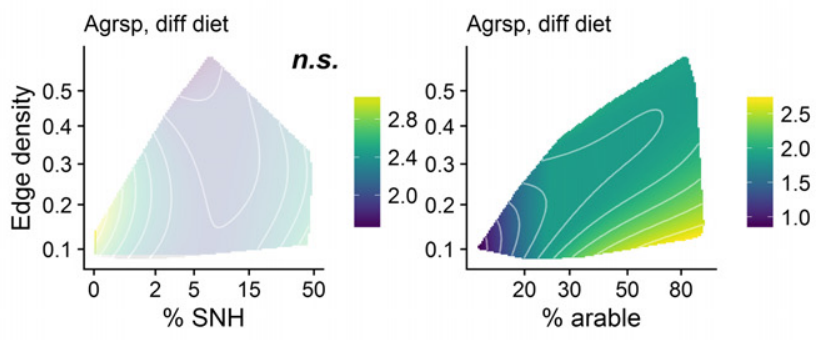

(c) Pests
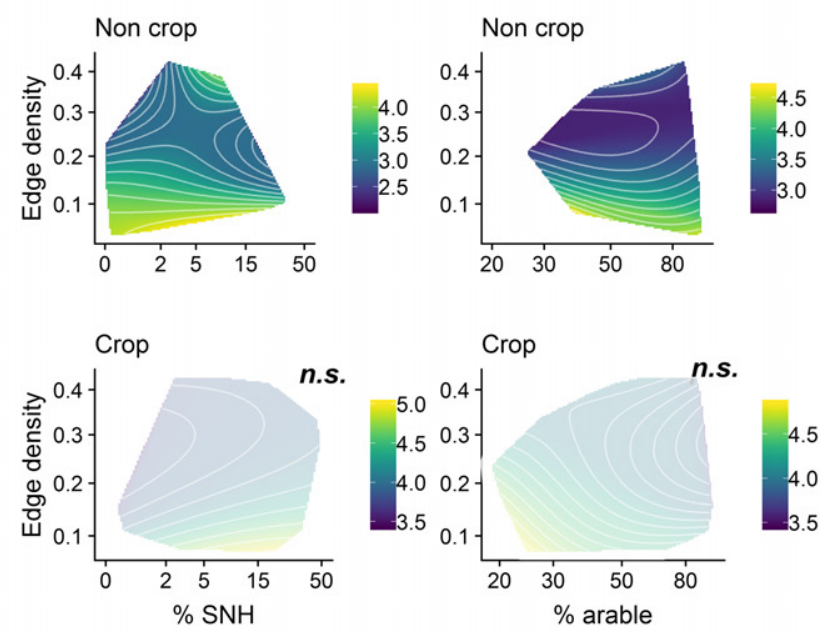

Figure 3 Heatmaps of the effects of landscape composition (\% SNH, left columns; \% arable land, right columns) and landscape configuration (edge density in $\mathrm{km} / \mathrm{ha}$ ) on the abundance of functional response groups of (a) natural enemies, (b) pollinators and (c) pests. Functional groups were separated into trait syndromes based on cluster regression of six categorical traits (see abbreviations in Table 1; Figs S2 and 3). Estimates and 95\% CI are shown at all radii in Fig. S5; results are shown here at the $1 \mathrm{~km}$ radius. See further graph details in the legend of Fig. 2.

\section{Trait syndromes of enemies, pollinators and pests}

Trait syndromes obtained by cluster regression varied between enemies, pollinators and pests, with the most clusters identified among natural enemies (Figs S3 and S4). Although scarce overall, effects of landscape predictors on enemies were significant across scales and highly contrasted between trait syndromes (Fig. 3a, S6). Three main patterns emerged: (1) Enemies 
(a) Pest control

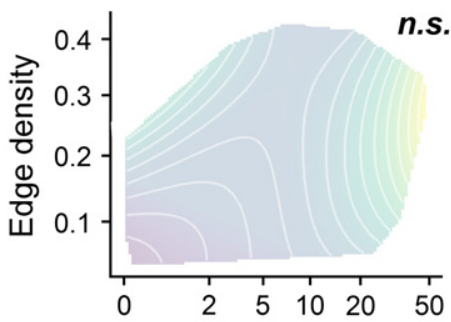

(b) Pollination

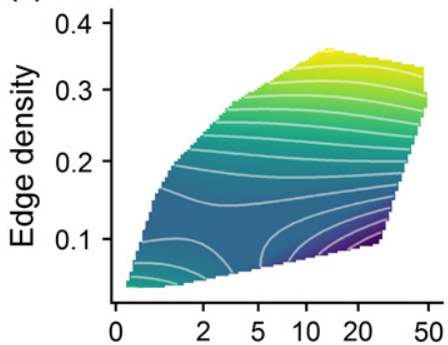

(c)

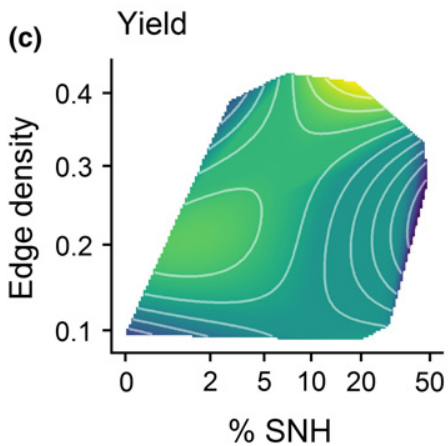

Pest control

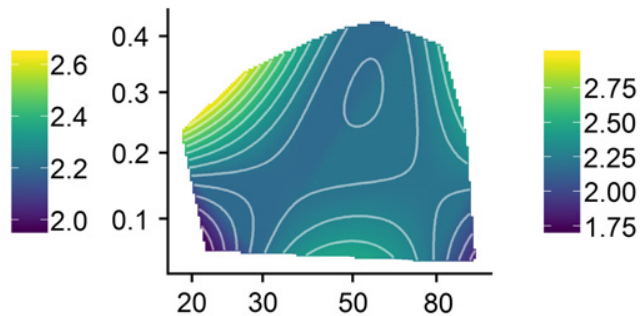

Pollination

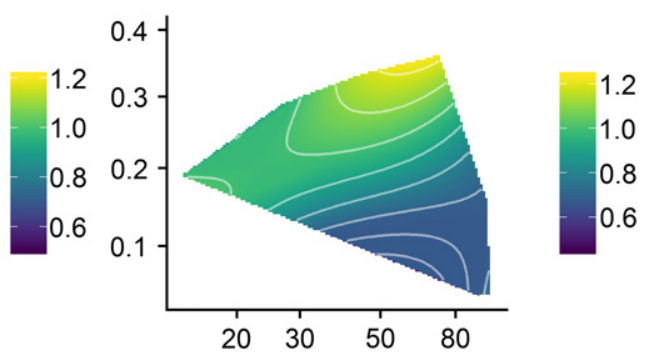

Yield

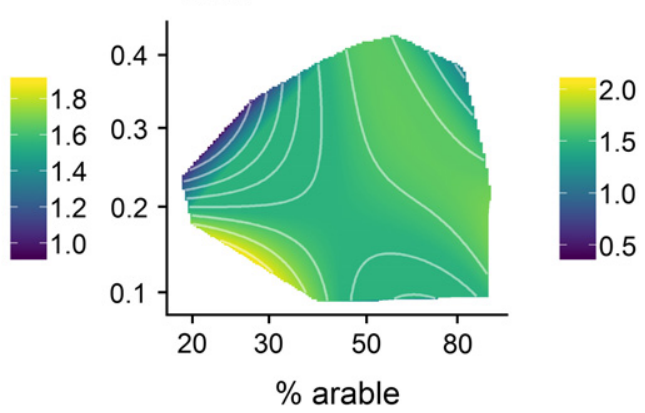

Figure 4 Heatmaps of the effects of landscape composition (\% SNH, left columns; \% arable land, right columns) and landscape configuration (edge density in $\mathrm{km} / \mathrm{ha}$ ) on (a) pest control, (b) pollination and (c) crop yield in weight per unit area. Response variables represent an ecosystem service index accounting for differences in methods within and between studies (see Appendix S1). See Table S3 for detailed units and measurements per study. Blue: lowest service provision; yellow: highest service provision. Estimates and 95\% CI are shown at all radii in Fig. S6; results are shown here at the $1 \mathrm{~km}$ radius. See further graph details in the legend of Fig. 2.

overwintering outside crops, including flight and ground-dispersers ( 327 species, $44 \%$ of enemies), benefited from high edge density. This was especially true in landscapes with $<10 \% \mathrm{SNH}$ for flyers, and $<60 \%$ arable land for ground-dispersers (Fig. 3a, S6). These groups increased with increasing \% SNH and decreasing $\%$ arable land, but effects depended on edge density - they occurred at low (flight) or high edge density (ground-dispersers). (2) In contrast, enemies able to overwinter in crops were most abundant in landscapes with few edges (Fig. 3a, S6). Among these, ground-dispersers benefited from high \% arable land, but flyers benefited from high \% SNH. (3) Effects of landscape predictors on wind-dispersers, mainly ballooning spiders and parasitoid wasps (flight/wind), were scarce.

Different responses also emerged among pollinators. Similar to all arthropods, non-agricultural specialist pollinators increased with high edge density at high or low \% SNH (Fig. 3b, S6; 393 species, $70 \%$ of pollinators). In contrast, agricultural specialists (e.g. aphidophagous syrphids) were most abundant in landscapes with few edges and high $\%$ arable land.
Pests able to overwinter in crops showed few effects of landscape variables across scales. However, pests considered to leave crops over winter were six times less abundant in landscapes with high edge density $(0.2-0.4 \mathrm{~km} / \mathrm{ha})$, regardless of their composition (Fig 3c, S6). Due to an increase beyond this range at intermediate $\% \mathrm{SNH}, 0.2-0.4 \mathrm{~km} / \mathrm{ha}$ of edges represented an area of minimum pest density along the observed gradients.

Marginal $R^{2}$ of models including trait syndromes averaged 0.11 , SD 0.07 (mean maximal $R^{2} \mathrm{~m}$ across scales). Thereby, landscape predictors had significantly higher explanatory power when applied to trait syndromes within functional groups than to whole groups of natural enemies, pollinators and pests (Wilcoxon rank-sum test, $\mathrm{W}=1289, P<0.001$ ).

\section{Pest control, pollination and yields}

Pest control, pollination and yields are given for a subset of studies (Tables S3, S6; Fig. 4, Fig. S7). Pest control by natural 
enemies was highest in landscapes with low \% arable land $(<40 \%)$ and high edge density, where it increased 1.4 -fold compared to landscapes with low edge density. It was lowest in coarse-grained landscapes (low edge density) with either low or high $\%$ arable land (Fig. 4a). Pollination increased with edge density; it was 1.7 times higher in fine-grained compared to coarse-grained landscapes regardless of $\% \mathrm{SNH}$ or $\%$ arable land. Low pollination was observed in landscapes with $>70 \%$ arable land and at edge densities $<0.1 \mathrm{~km} / \mathrm{ha}$ (Fig. 4b right panel). Yields showed a variable pattern (Fig. 4c, S7). They were highest in landscapes with 10-20\% SNH at high edge density (Fig. 4c left panel). Lowest yields were achieved in landscapes with $<40 \%$ arable land and high edge density (Fig. 4c right panel). In a range of landscapes including a large range of edge density and \% arable land, intermediate to high yields were maintained. The variance explained by landscape predictors in models of pest control, pollination and yields averaged 0.14 , SD 0.08 (mean maximal $R^{2}$ m across scales; mean maximal $R^{2}$ c 0.60 , SD 0. 09).

Additional analyses show that effects occurred mainly across full gradients instead of within standardised landscape ranges and were robust to standardisation of response variables (Appendix S3) as well as to the analytical method chosen (Appendix S4).

\section{DISCUSSION}

This synthesis shows that the response of arthropod abundance and services to landscape predictors is nonlinear across Europe and depends on interactions between landscape composition and configuration, and on the response traits of arthropods. Overall, arthropods were most abundant in landscapes that combine high edge density with high proportions of semi-natural habitat. Functional groups of pollinators, enemies and pests did not strongly reflect this pattern. Rather, trait syndromes within groups showed contrasting trends. Pollinators that do not feed on pests or crops as larvae (non-pest butterflies, non-aphidophagous syrphids, bees), and flying and ground-dwelling enemies considered to overwinter mainly outside crops, benefited from high edge density at low or high habitat amount and may require a high density of ecotones as exchange interfaces in order to spillover between and into crops (Concepción et al. 2012; Tscharntke et al. 2012; Hass et al. 2018). For organisms with limited dispersal ability, this requirement is likely due to the need to recolonise crops in spring. However, the same driver affected strong aerial dispersers such as wasps and butterflies, for which it may be more related to a high sensitivity to disturbance within fields and/or to the need for resource complementation through a high diversity of available plants and prey (Sutter et al. 2017) or nesting sites. Such diverse resources can not only be found in neighbouring semi-natural habitats (e.g. nest sites; Holland et al. 2016) but also in adjoining crops (pollen and nectar from crops and weeds, host plants or prey for herbivores and predators). Indeed, a high number of separate field units is the first requirement to support a high diversity of arable crops at organism-relevant scales. Landscapes with high vs. low edge density may also differ in their crop composition and/or diversity, with associated impacts on the arthropod community.
In contrast, ground-dispersing enemies with generalist overwintering needs, and pollinators whose larvae feed on crops or pests, were most abundant in landscapes with few edges and high $\%$ arable land. These groups benefit from agricultural resources and were able to maintain populations in coarsegrained landscapes with high \% arable land that other organisms avoided. They thus represent important insurance organisms contributing to arthropod response diversity (Cariveau et al. 2013) and may continue to provide services in coarsegrained landscapes with little non-crop habitat (Rader et al. 2016; but see Stavert et al. 2017). However, abundances were too low for these trends to be reflected in overall patterns. In addition, pests also benefited from landscapes with low edge density. The services provided by agriculture-resilient enemies and pollinators are thus likely insufficient to balance the bottom-up effects of high crop resource availability on pests in such low complexity landscapes (Walker \& Jones 2003).

Pests overwintering outside crops were least abundant, and pollination and pest control were highest, in landscapes with high edge density, particularly within the range of $0.2-0.4 \mathrm{~km} /$ ha. In agreement with Rusch et al. (2016), pest control was also highest at low \% arable land. However, for pests and pollination, edge density effects occurred largely independently of landscape composition. Based on trait syndrome patterns, pest control and pollination appear to have been largely driven by organisms without strong links to agricultural resources, which benefitted from high edge density to spillover and provide services in crops (ground- and, to a lesser extent, flight-dispersing enemies overwintering outside crops for pest control; non-agricultural specialists for pollination). Due to positive impacts on services and many service providers and negative impacts on pests, edge density thus appeared a more consistent driver for functional biodiversity and service provision than the presence of semi-natural habitat alone (Concepción et al. 2012). High diversity of arthropod service providers in such landscapes, confirmed by a positive correlation between abundance and species richness, may further imply functional redundancy. As a result, services supported by these landscapes may be more resilient to environmental change (Oliver et al. 2015, Martin et al. 2019).

Landscapes with high edge density did not have lower yields/ area than coarse-grained landscapes, in a large portion of composition gradients with varying $\% \mathrm{SNH}$ and arable land. Although only available from a subset of the data (Table S6), this result indicates that high edge density and its benefits can be combined with maintaining crop yields, within the range of edge density observed here. Accordingly, productive landscapes with edge density between 0.2 and $0.4 \mathrm{~km} / \mathrm{ha}$ may be ideally suited to implement ecological intensification. Cascading (positive) effects on yields of higher service provision and less pests in landscapes with high edge density were not, however, apparent from the available data. Reduced pollination and pest control at low edge density may have been compensated by external inputs in productive landscapes. In addition, other factors combine to impact yields (Gagic et al. 2017) and may mask the impact of biodiversity-driven services in the absence of careful standardisation (Pywell et al. 2015). Intermediate to low yields in landscapes with high \% arable, low \% SNH and low edge density may underpin the risks of ongoing conventional 
intensification resulting in yield stagnation or reduction despite high agricultural inputs (Ray et al. 2012).

Nonlinear and interacting effects of landscape predictors denote the importance of variation in the ranges occupied by European landscape gradients between studies. In combination with trait-based response syndromes, these results explain several inconsistencies highlighted in previous work (Kennedy et al. 2013; Veres et al. 2013; Díaz \& Concepción 2016; Holzschuh et al. 2016; Rader et al. 2016; Tscharntke et al. 2016; Karp et al. 2018). By covering a wide range of landscapes and responses, this study helps resolve why responses to landscape configuration and composition of arthropod functional groups differ along landscape gradients. In particular, we show that landscape effects and the potential effectiveness of landscape management measures vary according to the ranges of landscape variables captured in each study region, in agreement with theory underlying nonlinear responses of organisms to landscape gradients (Concepción et al. 2012). Increasing edge density was most effective for arthropods in landscapes with low $(<5 \%)$ or high $(>20 \%) \%$ SNH. In landscapes with intermediate \% $\mathrm{SNH}$, small increases in $\mathrm{SNH}$ may dilute populations, before reaching sufficient levels to contribute positively to spillover into fields. In these landscapes, extensive practices such as low-input farming may be the most effective way to enhance arthropod diversity and services in crops (Jonsson et al. 2015). Contrary to our hypotheses (Fig. 1), few effects were hump shaped within the range of tested gradients; thus, maxima may not be reached within the measured European gradients.

We applied a trait-based framework for agroecosystem communities using response traits that have not been considered in previous work on pollinators (Williams et al. 2010; De Palma et al. 2015; Carrié et al. 2017) or grassland arthropods (GámezVirués et al. 2015), but were important determinants of species' responses to landscape structure. We found that syndromes combining several response traits effectively disentangled pollinator, pest and enemy responses compared to single-trait approaches. Considering such traits with strong mechanistic underpinnings (Bartomeus et al. 2018) will increase our ability to derive predictions of the effects of environmental change on communities. Clarification is needed, however, on which trait syndromes correlate with strong impacts on service provision in crops. For instance, non-bees may complement bees for provision of pollination services (Rader et al. 2016), but the separate contribution of non-bee pollinators in intensive landscapes is unknown, and according to our results, may be considerably lower. In addition, relative contributions to pest control of natural enemies with different landscape responses, and the importance of high enemy diversity for pest control in real-world landscapes, have yet to be elucidated.

\section{CONCLUSION}

In this synthesis across Europe, we show that within European gradients, a high edge density is beneficial for a wide range of arthropods and the services they provide, and can be combined with high yields in productive landscapes with over $50 \%$ arable land. In addition to managing semi-natural habitat amounts, increasing the edge density of these landscapes is a promising pathway to combine the maintenance of arthropod biodiversity and services with continued and sustainable agricultural production. While the strength of these effects for arthropods depends on habitat amount, fine-grained landscapes provided benefits such as less pests and more pollination, which were largely independent of their composition. We further demonstrate a high response diversity of arthropod service providers leading to differing impacts of landscape change within groups of natural enemies, pests and pollinators. We thus call for consideration of mechanism-relevant response traits to catalyse modelling and prediction of the consequences of land-use change on arthropods and ecosystem services in crops.

\section{ACKNOWLEDGEMENTS}

We thank all farmers, field and technical assistants, researchers and funders who contributed to the studies made available for this synthesis. F. Bötzl and L. Pfiffner provided expertise and data on carabid traits. M. O'Rourke provided expertise on pest traits. A. Kappes, S. König and D. Senapathi provided technical support. We thank all members of the SocioEnvironmental Synthesis Center working group on 'Decisionmaking tools for pest control' led by D. Karp and B. Chaplin-Kramer for fruitful discussions in the process of creating this paper. We are grateful to three anonymous reviewers and to the editor for constructive comments on a previous version of the manuscript. Funding was provided by the European Union to the FP7 project LIBERATION (grant 311781) and by the 2013-2014 BiodivERsA/FACCE-JPI joint call for research proposals (project ECODEAL), with the national funders ANR, BMBF, FORMAS, FWF, MINECO, NWO and PT-DLR. E.D.C., M.Díaz and G.M. acknowledge the project BIOGEA (PCIN-2016-159, BiodivERsA3 with the national funders BMBF, MINECO, BNSF).

\section{AUTHOR CONTRIBUTIONS}

EAM, ISD, MD, YC, AB, RB, VG, MG, AH, DK, AK, LM, SP and HS designed the study. DAH, SA, MA, GKSA, MAZ, JDA, AB, MB, LBP, IB, PB, RB, FB, BCL, YC, EDC, VC, MD, JD, MDíaz, TD, CFD, RD, MHE, NF, CF, TF, VG, LAG, MG, JH, FH, AH, DI, KJ, FJ, PJ, MK, DK, AKH, JK, VLF, LM, JM, ACM, GM, SP, VR, MR, AR, JS, GS, CS, HS, ISD, SS, LS, GT, CT, JT, TT, MT, DU and CW performed the research. EAM analysed the data. EAM, ISD, MD and YC interpreted results. EAM wrote the paper and all authors contributed substantially to revisions.

\section{DATA ACCESSIBILITY STATEMENT}

The data supporting the results are archived at https://doi. org/10.5061/dryad.6tj407n

\section{REFERENCES}

Bartomeus, I., Cariveau, D.P., Harrison, T. \& Winfree, R. (2018). On the inconsistency of pollinator species traits for predicting either response to land-use change or functional contribution. Oikos, 127, 306-315. 
Bates, D., Mächler, M., Bolker, B. \& Walker, S. (2015). Fitting linear mixed-effects models using lme4. J. Stat. Softw., 67, 1-48.

Blitzer, E.J., Dormann, C.F., Holzschuh, A., Klein, A.-M., Rand, T.A. \& Tscharntke, T. (2012). Spillover of functionally important organisms between managed and natural habitats. Agric. Ecosyst. Environ., 146, $34-43$.

Boetzl, F.A., Krimmer, E., Krauss, J. \& Steffan-Dewenter, I. (2019). Agri-environmental schemes promote ground-dwelling predators in adjacent oilseed rape fields: diversity, species traits and distance-decay functions. J. Appl. Ecol., 56, 10-20.

Bommarco, R., Kleijn, D. \& Potts, S.G. (2013). Ecological intensification: Harnessing ecosystem services for food security. Trends Ecol. Evol., 28, 230-238.

Bosem Baillod, A., Tscharntke, T., Clough, Y. \& Batáry, P. (2017). Landscape-scale interactions of spatial and temporal cropland heterogeneity drive biological control of cereal aphids. J. Appl. Ecol., 54, 1804-1813.

Cariveau, D.P., Williams, N.M., Benjamin, F.E. \& Winfree, R. (2013). Response diversity to land use occurs but does not consistently stabilise ecosystem services provided by native pollinators. Ecol. Lett., 16, 903-911.

Carrié, R., Andrieu, E., Cunningham, S.A., Lentini, P.E., Loreau, M. \& Ouin, A. (2017). Relationships among ecological traits of wild bee communities along gradients of habitat amount and fragmentation. Ecography, 40, 85-97.

Chaplin-Kramer, R., O'Rourke, M.E., Blitzer, E.J. \& Kremen, C. (2011). A meta-analysis of crop pest and natural enemy response to landscape complexity. Ecol. Lett., 14, 922-932.

Concepción, E.D., Díaz, M., Kleijn, D., Báldi, A., Batáry, P., Clough, Y. et al. (2012). Interactive effects of landscape context constrain the effectiveness of local agri-environmental management. J. Appl. Ecol., 49, 695-705.

Coudrain, V., Schüepp, C., Herzog, F., Albrecht, M. \& Entling, M.H. (2014). Habitat amount modulates the effect of patch isolation on hostparasitoid interactions. Front. Environ. Sci., 2, 27.

De Palma, A., Kuhlmann, M., Roberts, S.P.M., Potts, S.G., Börger, L., Hudson, L.N. et al. (2015). Ecological traits affect the sensitivity of bees to land-use pressures in European agricultural landscapes. J. Appl. Ecol., 52, 1567-1577.

Díaz, M. \& Concepción, E.D. (2016). Enhancing the effectiveness of CAP greening as a conservation tool: a plea for regional targeting considering landscape constraints. Curr. Landsc. Ecol. Rep., 1, 168-177.

Duflot, R., Aviron, S., Ernoult, A., Fahrig, L. \& Burel, F. (2015). Reconsidering the role of 'semi-natural habitat' in agricultural landscape biodiversity: a case study. Ecol. Res., 30, 75-83.

Dunning, J.B., Danielson, B.J. \& Pulliam, H.R. (1992). Ecological processes that affect populations in complex landscapes. Oikos, 65, $169-175$.

Fahrig, L. (2013). Rethinking patch size and isolation effects: the habitat amount hypothesis. J. Biogeogr., 40, 1649-1663.

Fahrig, L. (2017). Ecological responses to habitat fragmentation per se. Annu. Rev. Ecol. Evol. Syst., 48, 1-23.

Fahrig, L., Girard, J., Duro, D., Pasher, J., Smith, A., Javorek, S. et al. (2015). Farmlands with smaller crop fields have higher within-field biodiversity. Agric. Ecosyst. Environ., 200, 219-234.

Foley, J.A., DeFries, R., Asner, G.P., Barford, C., Bonan, G., Carpenter, S.R. et al. (2005). Global consequences of land use. Science, 309, 570-574.

Gagic, V., Kleijn, D., Báldi, A., Boros, G., Jørgensen, H.B., Elek, Z. et al. (2017). Combined effects of agrochemicals and ecosystem services on crop yield across Europe. Ecol. Lett., 20, 1427-1436.

Gámez-Virués, S., Perović, D.J., Gossner, M.M., Börschig, C., Blüthgen, N., de Jong, H. et al. (2015). Landscape simplification filters species traits and drives biotic homogenization. Nat. Commun., 6, 8568.

Garnett, T., Appleby, M.C., Balmford, A., Bateman, I.J., Benton, T.G., Bloomer, P. et al. (2013). Sustainable Intensification in Agriculture: premises and Policies. Science, 341, 33-34.

Geiger, F., Bengtsson, J., Berendse, F., Weisser, W.W., Emmerson, M., Morales, M.B. et al. (2010). Persistent negative effects of pesticides on biodiversity and biological control potential on European farmland. Basic Appl. Ecol., 11, 97-105.

Gelman, A. \& Su, Y.-S. (2016). arm: Data Analysis Using Regression and Multilevel/Hierarchical Models. R package version 1.9-3. https:// CRAN.R-project.org $/$ package $=$ arm.

Haddad, N.M., Gonzalez, A., Brudvig, L.A., Burt, M.A., Levey, D.J. \& Damschen, E.I. (2017). Experimental evidence does not support the Habitat Amount Hypothesis. Ecography, 40, 48-55.

Hainmueller, J., Mummolo, J. \& Xu, Y. (2018). How Much Should We Trust Estimates from Multiplicative Interaction Models? Simple Tools to Improve Empirical Practice(SSRN Scholarly Paper No. ID 2739221). Social Science Research Network, Rochester, NY.

Hass, A.L., Kormann, U.G., Tscharntke, T., Clough, Y., Baillod, A.B., Sirami, C. et al. (2018). Landscape configurational heterogeneity by small-scale agriculture, not crop diversity, maintains pollinators and plant reproduction in western Europe. Proc. R. Soc. B, 285, 20172242.

Holland, J.M., Bianchi, F.J., Entling, M.H., Moonen, A.-C., Smith, B.M. \& Jeanneret, P. (2016). Structure, function and management of seminatural habitats for conservation biological control: a review of European studies. Pest Manag. Sci., 72, 1638-1651.

Holzschuh, A., Steffan-Dewenter, I. \& Tscharntke, T. (2010). How do landscape composition and configuration, organic farming and fallow strips affect the diversity of bees, wasps and their parasitoids? J. Anim. Ecol., 79, 491-500.

Holzschuh, A., Dainese, M., González-Varo, J.P., Mudri-Stojnić, S., Riedinger, V., Rundlöf, M. et al. (2016). Mass-flowering crops dilute pollinator abundance in agricultural landscapes across Europe. Ecol. Lett., 19, 1228-1236.

Jonsson, M., Straub, C.S., Didham, R.K., Buckley, H.L., Case, B.S., Hale, R.J. et al. (2015). Experimental evidence that the effectiveness of conservation biological control depends on landscape complexity. $J$. Appl. Ecol., 52, 1274-1282.

Karp, D.S., Chaplin-Kramer, R., Meehan, T.D., Martin, E.A., DeClerck, F., Grab, H. et al. (2018). Crop pests and predators exhibit inconsistent responses to surrounding landscape composition. Proc. Natl Acad. Sci., 115, E7863-E7870.

Kennedy, C.M., Lonsdorf, E., Neel, M.C., Williams, N.M., Ricketts, T.H., Winfree, R. et al. (2013). A global quantitative synthesis of local and landscape effects on wild bee pollinators in agroecosystems. Ecol. Lett., 16, 584-599.

Kleijn, D., Bommarco, R., Fijen, T.P.M., Garibaldi, L.A., Potts, S.G. \& van der Putten, W.H. (2019). Ecological intensification: bridging the gap between science and practice. Trends Ecol. Evol., 34, 154-166.

Kleyer, M., Dray, S., Bello, F., Lepš, J., Pakeman, R.J., Strauss, B. et al. (2012). Assessing species and community functional responses to environmental gradients: which multivariate methods? J. Veg. Sci., 23, 805-821.

Lavorel, S. \& Garnier, E. (2002). Predicting changes in community composition and ecosystem functioning from plant traits: revisiting the Holy Grail. Funct. Ecol., 16, 545-556.

Martin, E.A., Seo, B., Park, C.-R., Reineking, B. \& Steffan-Dewenter, I. (2016). Scale-dependent effects of landscape composition and configuration on natural enemy diversity, crop herbivory, and yields. Ecol. Appl., 26, 448-462.

Martin, E.A., Feit, B., Requier, F., Friberg, H. \& Jonsson, M. (2019). Assessing the resilience of biodiversity-driven functions in agroecosystems under environmental change. Adv. Ecol. Res., 60, in press (accepted).

Mouillot, D., Graham, N.A.J., Villéger, S., Mason, N.W.H. \& Bellwood, D.R. (2013). A functional approach reveals community responses to disturbances. Trends Ecol. Evol., 28, 167-177.

Nakagawa, S. \& Schielzeth, H. (2013). A general and simple method for obtaining R2 from generalized linear mixed-effects models. Methods Ecol. Evol., 4, 133-142.

Naylor, R. \& Ehrlich, P.R. (1997). Natural pest control services and agriculture. In: Nature's services: societal dependance on natural 
ecosystems. (ed Daily, G.). Island Press, Washington D.C., U.S.A., pp. $151-174$.

Oliver, T.H., Isaac, N.J.B., August, T.A., Woodcock, B.A., Roy, D.B. \& Bullock, J.M. (2015). Declining resilience of ecosystem functions under biodiversity loss. Nat. Commun., 6, 10122.

Pascual-Hortal, L. \& Saura, S. (2007). Impact of spatial scale on the identification of critical habitat patches for the maintenance of landscape connectivity. Landsc. Urban Plan., 83, 176-186.

Perović, D., Gámez-Virués, S., Börschig, C., Klein, A.-M., Krauss, J., Steckel, J. et al. (2015). Configurational landscape heterogeneity shapes functional community composition of grassland butterflies. J. Appl. Ecol., 52, 505-513.

Perović, D.J., Gámez-Virués, S., Landis, D.A., Wäckers, F., Gurr, G.M., Wratten, S.D. et al. (2018). Managing biological control services through multi-trophic trait interactions: review and guidelines for implementation at local and landscape scales. Biol. Rev., 93, 306-321.

Plećaš, M., Gagić, V., Janković, M., Petrović-Obradović, O., Kavallieratos, N.G., Tomanović, Ž. et al. (2014). Landscape composition and configuration influence cereal aphid-parasitoidhyperparasitoid interactions and biological control differentially across years. Agric. Ecosyst. Environ., 183, 1-10.

Pywell, R.F., Heard, M.S., Woodcock, B.A., Hinsley, S., Ridding, L., Nowakowski, M. et al. (2015). Wildlife-friendly farming increases crop yield: evidence for ecological intensification. Proc. R. Soc. B, 282, 20151740.

R Core Team. (2017). R: A language and environment for statistical computing. R Foundation for Statistical Computing, Vienna, Austria.

Rader, R., Bartomeus, I., Garibaldi, L.A., Garratt, M.P., Howlett, B.G., Winfree, R. et al. (2016). Non-bee insects are important contributors to global crop pollination. Proc. Natl Acad. Sci., 113, 146-151.

Ray, D.K., Ramankutty, N., Mueller, N.D., West, P.C. \& Foley, J.A. (2012). Recent patterns of crop yield growth and stagnation. Nat. Commun., 3, 1293.

Rusch, A., Chaplin-Kramer, R., Gardiner, M.M., Hawro, V., Holland, J., Landis, D. et al. (2016). Agricultural landscape simplification reduces natural pest control: a quantitative synthesis. Agric. Ecosyst. Environ., 221, 198-204.

Schellhorn, N.A., Gagic, V. \& Bommarco, R. (2015). Time will tell: resource continuity bolsters ecosystem services. Trends Ecol. Evol., 30, 524-530.

Seppelt, R., Beckmann, M., Ceauşu, S., Cord, A.F., Gerstner, K., Gurevitch, J. et al. (2016). Harmonizing biodiversity conservation and productivity in the context of increasing demands on landscapes. Bioscience, 66, 890-896.

Smith, H.G., Birkhofer, K., Clough, Y., Ekroos, J., Olsson, O. \& Rundlöf, M. (2014). Beyond dispersal: the role of animal movement in modern agricultural landscapes. In: Animal Movement Across Scales (ed Hansson, L.-A. Åkesson, S.), Oxford University Press, Oxford, U.K., pp. 51-70.

Stavert, J.R., Pattemore, D.E., Gaskett, A.C., Beggs, J.R. \& Bartomeus, I. (2017). Exotic species enhance response diversity to land-use change but modify functional composition. Proc. R. Soc. B, 284, 20170788.
Sutter, L., Jeanneret, P., Bartual, A.M., Bocci, G. \& Albrecht, M. (2017). Enhancing plant diversity in agricultural landscapes promotes both rare bees and dominant crop-pollinating bees through complementary increase in key floral resources. J. Appl. Ecol., 54, 1856-1864.

Tscharntke, T., Tylianakis, J.M., Rand, T.A., Didham, R.K., Fahrig, L., Batary, P. et al. (2012). Landscape moderation of biodiversity patterns and processes-eight hypotheses. Biol. Rev., 87, 661-685.

Tscharntke, T., Karp, D.S., Chaplin-Kramer, R., Batáry, P., DeClerck, F., Gratton, C. et al. (2016). When natural habitat fails to enhance biological pest control - Five hypotheses. Biol. Conserv., 204, Part B, 449-458.

Van de Pol, M. \& Wright, J. (2009). A simple method for distinguishing within-versus between-subject effects using mixed models. Anim. Behav., $77,753$.

Vasseur, C., Joannon, A., Aviron, S., Burel, F., Meynard, J.-M. \& Baudry, J. (2013). The cropping systems mosaic: how does the hidden heterogeneity of agricultural landscapes drive arthropod populations? Agric. Ecosyst. Environ., 166, 3-14.

Veres, A., Petit, S., Conord, C. \& Lavigne, C. (2013). Does landscape composition affect pest abundance and their control by natural enemies? A review. Agric. Ecosyst. Environ., 166, 110-117.

Walker, M. \& Jones, T.H. (2003). Relative roles of top-down and bottom-up forces in terrestrial tritrophic plant-insect herbivore-natural enemy systems. Oikos, 93, 177-187.

Williams, N.M., Crone, E.E., T'ai, H.R., Minckley, R.L., Packer, L. \& Potts, S.G. (2010). Ecological and life-history traits predict bee species responses to environmental disturbances. Biol. Conserv., 143, 22802291.

Winfree, R., W Fox, J., Williams, N.M., Reilly, J.R. \& Cariveau, D.P. (2015). Abundance of common species, not species richness, drives delivery of a real-world ecosystem service. Ecol. Lett., 18, 626-635.

Wratten, S.D., Bowie, M.H., Hickman, J.M., Evans, A.M., Sedcole, J.R. \& Tylianakis, J.M. (2003). Field boundaries as barriers to movement of hover flies (Diptera: Syrphidae) in cultivated land. Oecologia, 134, 605611.

Zuur, A.F., Ieno, E.N., Walker, N.J., Saveliev, A.A. \& Smith, G.M. (2009). Mixed Effects Models and Extensions in Ecology with R. New York: Springer. $574 \mathrm{P}$.

\section{SUPPORTING INFORMATION}

Additional supporting information may be found online in the Supporting Information section at the end of the article.

Editor, Christoph Scherber

Manuscript received 13 August 2018

First decision made 24 September 2018

Second decision made 13 January 2019

Manuscript accepted 8 March 2019 